\title{
Profound Alterations in the Intrinsic Excitability of Cerebellar Purkinje Neurons Following Neurotoxin 3-Acetylpyridine (3-AP)- Induced Ataxia in Rat: New Insights Into the Role of Small Conductance $\mathrm{K}^{+}$Channels
}

\author{
M. KAFFASHIAN ${ }^{1,2}$, M. SHABANI ${ }^{3}$, I. GOUDARZI ${ }^{4}$, G. BEHZADI ${ }^{1}$, A. ZALI $^{3}$, \\ M. JANAHMADI ${ }^{1}$
}

${ }^{1}$ Neuroscience Research Center and Department of Physiology, Medical School, Shahid Beheshti University of Medical Sciences, Evin, Tehran, Iran, ${ }^{2}$ Department of Physiology, Faculty of Medicine, Ilam University of Medical Sciences, Ilam, Iran, ${ }^{3}$ Neuroscience Research Center and Physiology Research Center, Kerman University of Medical Sciences, Kerman, Iran, ${ }^{4}$ Department of Biology, Damghan University of Basic Sciences, Damghan, Iran, ${ }^{5}$ Department of Neurosurgery, Shohada Hospital, Shahid Beheshti University of Medical Sciences, Tehran, Iran

Received May 17, 2010

Accepted September 17, 2010

On-line November 29, 2010

\section{Summary}

Alterations in the intrinsic properties of Purkinje cells (PCs) may contribute to the abnormal motor performance observed in ataxic rats. To investigate whether such changes in the intrinsic neuronal excitability could be attributed to the role of $\mathrm{Ca}^{2+}$-activated $\mathrm{K}^{+}$channels $\left(\mathrm{K}_{\mathrm{Ca}}\right)$, whole cell current clamp recordings were made from $\mathrm{PCS}$ in cerebellar slices of control and ataxic rats. 3-AP induced profound alterations in the intrinsic properties of PCs, as evidenced by a significant increase in both the membrane input resistance and the initial discharge frequency, along with the disruption of the firing regularity. In control PCs, the blockade of small conductance $\mathrm{K}_{\mathrm{Ca}}$ channels by UCL1684 resulted in a significant increase in the membrane input resistance, action potential (AP) half-width, time to peak of the AP and initial discharge frequency. SK channel blockade also significantly decreased the neuronal discharge regularity, the peak amplitude of the AP, the amplitude of the afterhyperpolarization and the spike frequency adaptation ratio. In contrast, in ataxic rats, both the firing regularity and the initial firing frequency were significantly increased by the blockade of SK channels. In conclusion, ataxia may arise from alterations in the functional contribution of SK channels, to the intrinsic properties of PCs.

\begin{abstract}
Key words
Cerebellar ataxia - Intrinsic excitability - Neurotoxin 3-acetylpyridine - Purkinje neurons - Small conductance $\mathrm{Ca}^{2+}$-activated $\mathrm{K}^{+}$channels

\section{Corresponding author}

M. Janahmadi, Neuroscience Research Centre and Department of Physiology, Medical School, Shahid Beheshti University of Medical Sciences, Evin, Tehran, Iran. PO. Box 19615-1178. E-mail: mjanahmadi@yahoo.com or Janahmadi@sbmu.ac.ir
\end{abstract}

\section{Introduction}

Dysfunction or degeneration of Purkinje cells, the key neuronal cells of the cerebellar circuitry, causes ataxia. In our previous study, we showed that neurotoxin 3-acetylpyridine (3-AP) induced cerebellar ataxia, which was associated with motor incoordination and alterations in the morphological and intrinsic electrophysiological characteristics of Purkinje cells (Janahmadi et al. 2009). However, the cellular mechanisms underlying these changes have not yet been fully determined. Intrinsic neuronal excitability, which refers to the ability of a neuron to fire action potentials in the absence of synaptic 
inputs, could be directly attributed to the biochemical and electrophysiological properties of intrinsic membrane channels (Schulz 2006, Russo et al. 2008), so that alterations in the function of these channels may lead to plasticity in neuronal excitability and in neural circuits to which they belong. Among the wide range of ion channels, potassium channels, which are the largest and most diverse group of ion channels, play a main regulatory role in excitable cells. Consequently, malfunction of these channels can result in several neurological disorders, including ataxia. In animal models of ataxia, Sausbier et al. (2004) reported that $\mathrm{Ca}^{2+}$-activated $\mathrm{K}^{+}$channel deficiency causes dysfunction of Purkinje cells (PCs) and thereby results in cerebellar ataxia. At the cellular level, they showed that cerebellar Purkinje cells from mice lacking big conductance $\mathrm{K}^{+}$ channels display a dramatic reduction in spontaneous activity. A remarkable reduction in the amplitude of poststimulus afterhyperpolarization (AHP), which is linked to $\mathrm{Ca}^{2+}$-activated $\mathrm{K}^{+}$conductance, was also recently reported in a rat model of ataxia (Janahmadi et al. 2009). In many neurons of the central nervous system, including PCs, both large conductance $\mathrm{K}^{+}(\mathrm{BK})$ and small conductance $\mathrm{K}^{+}$(SK) channels are found (Shepard and Bunney 1991, Sah 1996, Shah and Haylett 2000, Cingolani et al. 2002, Faber and Sah 2002, Edgerton and Reinhart 2003, Haghdoost-Yazdi et al. 2007, Maingret et al. 2008), where they play an important role in the regulation of neuronal excitability. Although the physiological roles of calcium-dependent potassium channels have been well documented, their functional contribution to the pathophysiology of neurological diseases (e.g. ataxia) is still poorly understood. To assess the possible functional contribution of SK channels to the altered intrinsic electrical properties of Purkinje neurons in a rat model of cerebellar ataxia induced by 3-acetylpyridine (3-AP) (Janahmadi et al. 2009), the effect of UCL 1684, a potent SK channel blocker, was examined. 3-AP, which is a neurotoxin and a niacinamide receptor antagonist, it is known to be an effective agent that selectively destroys inferior olive neurons, the major source of the climbing fibres innervating the cerebellar Purkinje neurons (Balaban 1985, Torres-Aleman et al. 1996, Caddy and Vozeh 1997, Seoane et al. 2005). As a result, the cerebellar cortex loses its climbing fibre input, and the rats become ataxic (Llinás et al. 1975). It is welldocumented that the climbing input to a Purkinje neuron is essential for normal cerebellar function because it controls the intrinsic properties of the output of PCs
(Cerminara and Rawson 2004, McKay et al. 2007).

\section{Methods}

Fourteen Wistar rats (3 to 4 weeks old) were used in this study. The rats were divided into two groups consisted of 8 rats in control group and 6 rats in 3-APtreated group. All animals (were housed at $22{ }^{\circ} \mathrm{C}$ and maintained on a 12:12 h light/dark cycle with free access to food and water. All procedures for the maintenance and the use of the experimental animals were approved by the Institutional Ethics Committee (IEC) at the University of Shahid Beheshti Medical Sciences. To induce ataxia, rats were given a single i.p. $65 \mathrm{mg} / \mathrm{kg}$ dose of 3-acetylpyridine (Sigma-Aldrich) dissolved in physiological saline (Janahmadi et al. 2009). Our previous results showed that there was no significant difference between the behavioral responses in control (untreated) and vehicle (saline-treated) groups (Janahmadi et al. 2009, Goudarzi et al. 2010). Therefore, statistical comparison was performed between control (untreated) and 3-AP-treated groups. The dose of neurotoxin was chosen on the basis of previous studies demonstrating that it caused a severe motor impairment and induced cerebellar ataxia (Janahmadi et al. 2009). Next, the electrophysiological recordings were done at day 0 (pre-test) and one day after ataxia induction.

\section{Electrophysiology}

Animals were deeply anesthetized by inhalation of ether and then decapitated. The rat brains were rapidly removed and the cerebellar vermis was then dissected and placed in ice-cold artificial cerebrospinal fluid (ACSF) containing (in $\mathrm{mM}$ ): $124 \mathrm{NaCl}, 5 \mathrm{KCl}, 1.2 \mathrm{KH}_{2} \mathrm{PO}_{4}$, $1.3 \mathrm{MgSO}_{4}, 2.4 \mathrm{CaCl}_{2}, 26 \mathrm{NaHCO}_{3}$ and 10 glucose, bubbled continuously with carbogen gas (95\% oxygen and $5 \%$ carbon dioxide) to adjust the $\mathrm{pH}$ to 7.4. Parasagittal slices (300 $\mu \mathrm{m}$ thick) were cut from the vermis of rats using a vibroslicer (752M, Campden Instruments Ltd, UK). The slices were incubated at $36{ }^{\circ} \mathrm{C}$ for $>30 \mathrm{~min}$ and then stored at room temperature.

\section{Whole cell patch current clamp recording}

After recovery $(>1 \mathrm{~h})$ at $22-25{ }^{\circ} \mathrm{C}$, a single slice was transferred to a submerged chamber mounted on the stage of an upright microscope (Olympus; BX 51W) and continuously superfused with oxygenated ACSF. The flow rate was kept at 1-2 $\mathrm{ml} / \mathrm{min}$ using a peristaltic pump (Hugo Sachs Electronik, Ismatec, Germany). To study the 
intrinsic firing characteristics of Purkinje neurons, $1 \mathrm{mM}$ kynurenic acid and $100 \mu \mathrm{M}$ picrotoxin, the blockers of ionotropic glutamate (Stone 1993) and GABA (Yoon et al. 1993) receptors, respectively, were added to the recording ACSF. Whole cell patch clamp recordings using a Multiclamp 700B amplifier (Molecular Devices, Axon Instruments, Foster City, CA) in the current clamp mode were performed on the cerebellar Purkinje cells and were digitized with a Digidata computer interface (Axon Instruments). Neurons were visually identified by their shape and location using infrared differential interface contrast (IR-DIC) video microscopy with a 60x water immersion objective. The images were detected with an IR-sensitive CCD camera (Hamamatsu, ORSA, Japan) and displayed on a monitor.

Spontaneous activity was monitored with a whole cell patch pipette (resistance 3-6 M $\Omega$ ) pulled from borosilicate glass using a PC-10 puller (Narishige, Japan) and filled with a solution containing (in $\mathrm{mM}$ ): 135 potassium methyl sulphate $\left(\mathrm{KMeSO}_{4}\right), 10 \mathrm{KCl}$, 10 HEPES, $1 \mathrm{MgCl}_{2}, 2 \mathrm{Na}_{2} \mathrm{ATP}$, and $0.4 \mathrm{Na}_{2} \mathrm{GTP}$ (pH 7.2, adjusted with $\mathrm{KOH} ; 290 \mathrm{mOsm}$ ). After establishment of the G $\Omega$ seal, the whole cell configuration was achieved simply by the application of a brief suction to break through the membrane. Cells with a seal $<1 \mathrm{G} \Omega$ before the rupture of the membrane were discarded, and the test seal function was constantly monitored throughout the recording to ensure that the seal was stable. In addition, the series resistance (typically $<15 \mathrm{M} \Omega$ ) was checked for stability during the experiments. The signals were filtered at $10 \mathrm{kHz}$ and sampled at $20 \mathrm{kHz}$ using Clampex 9 software (Axon Instruments).

The membrane properties and action potential parameters were measured, including the firing regularity, action potential half-width, time to peak, and afterhyperpolarization (AHP) amplitude. In the current clamp mode, the instantaneous firing frequency and spike frequency adaptation (SFA) ratio were also measured. The regularity of the firing was assessed using the coefficient of variation (CV) of the interspike intervals, which was calculated as the ratio of the standard deviation to the mean. The action potential half-width was the time difference between the rising and falling phase of an action potential, measured at $50 \%$ of the amplitude of the spike. The instantaneous frequency was calculated as the inverse of the first interspike interval for the trains of action potential that were elicited by the injection of depolarizing current pulses (1600 ms duration, $0.1 \mathrm{nA}$ and $0.5 \mathrm{nA}$ ). The SFA ratio is equal to
$F_{\text {initial }} / F_{\text {final }}$, where $F_{\text {initial }}$ is the first instantaneous frequency, calculated from the first interspike interval, and $F_{\text {final }}$ is the final instantaneous frequency, calculated from the last interspike interval (Venance and Glowinski 2003). The amplitude of the AHP was measured from the baseline $(-60 \mathrm{mV})$ to the peak of the AHP. The resting input resistance was measured from the slope of a linear fit of the current-voltage curve of current-clamp recordings. The action potential properties were measured and compared while holding the cell membrane potential at $-60 \mathrm{mV}$.

All chemicals and drugs were obtained from Sigma (UK). Drugs were stored in a stock from which working solutions were prepared freshly every day. The doses of the drugs were chosen based on preliminary experiments using values from the literature (Daniel et al. 2004, Loewenstein et al. 2005, Moldavan et al. 2006).

\section{Statistical analysis}

Data are presented as the mean \pm S.E.M. Statistical comparisons were carried out using Student's $t$ test or a two-way analysis of variance (ANOVA) followed by a Tukey HSD post-hoc test. A $\mathrm{p} \leq 0.05$ was considered significant.

\section{Results}

3-acetylpyridine-induced profound alterations in the intrinsic membrane properties of Purkinje neurons

The present study examined how the intrinsic properties of Purkinje neurons were affected by 3-AP, a neurotoxin. Whole cell current clamp recordings were made from a total of 45 cerebellar Purkinje neurons in 14 rats; 25 neurons were recorded from eight control rats and 20 neurons were recorded from six rats treated with 3-AP.

In the control conditions, Purkinje cells displayed a regular firing pattern (Fig. 1Ai) with a mean input resistance of $73.35 \pm 0.45 \mathrm{M} \Omega$ (Fig. 2A) and mean coefficient of variation $(\mathrm{CV})$ of the interspike interval of $0.07 \pm 0.008$ ( $n=25$; Fig. 2B). In contrast, Purkinje neurons from 3-AP-treated rats discharged with an irregular pattern of activity, as evidenced by a significant increase in the $\mathrm{CV}(0.18 \pm 0.03, \mathrm{n}=15$; Figs $1 \mathrm{Bi}$ and $2 \mathrm{~B})$, and exhibited much larger input resistance $(81.51 \pm 3.96 \mathrm{M} \Omega$, $\mathrm{n}=20, \mathrm{P}<0.01$; Fig. 2A). The duration of the action potential at half the maximal amplitude was shortened significantly (from $0.72 \pm 0.03 \mathrm{~ms}$ to $0.54 \pm 0.001 \mathrm{~ms}$, $\mathrm{P}<0.05$; Fig. 2C), and the time to peak was significantly 


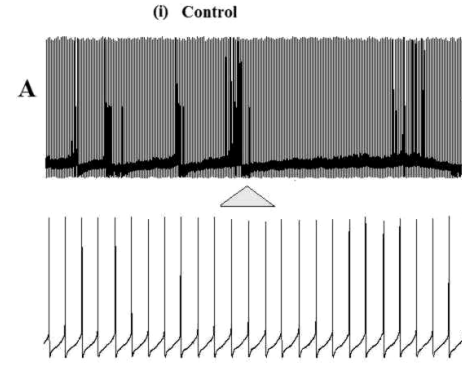

(i) 3-AP

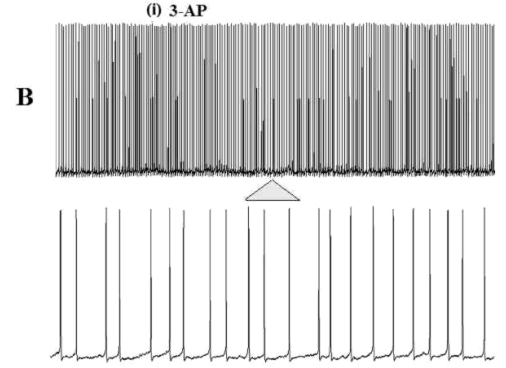

(ii) Control + UCL1684
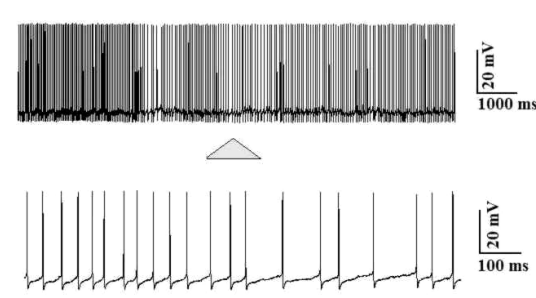

(ii) 3-AP+UCL1684
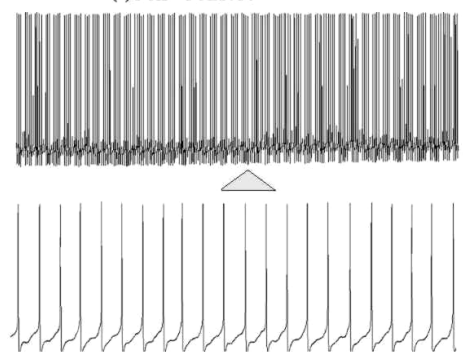

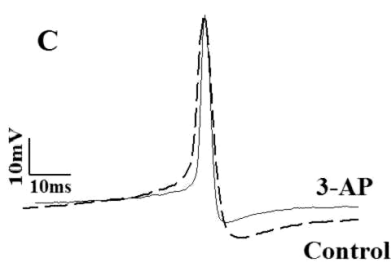

D
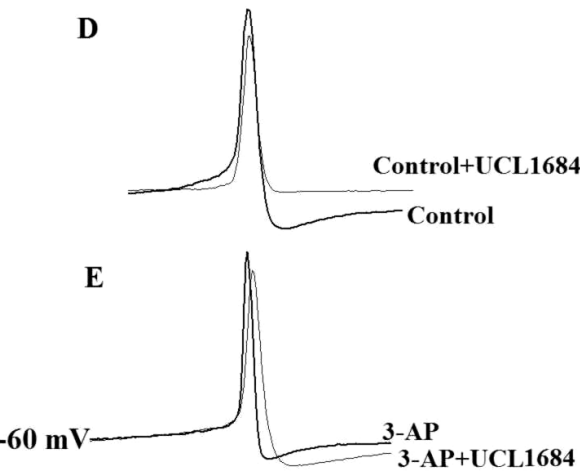

Fig. 1. Profound changes in the intrinsic firing properties of Purkinje neurons were induced in an animal model of ataxia by injection with 3-AP. A(i), somatic whole cell patch clamp recording of spontaneous intrinsic firing under the control condition and $\mathbf{A}(\mathbf{i i )}$ in the presence of UCL $1684(60 \mathrm{nM})$. The regularity of firing is shown on an expanded time scale (lower traces). B(i) intrinsic spontaneous firing pattern of PCs recorded from 3-AP-treated rats and B(ii) following the application of UCL 1684 (60 nM). The change in firing precision is shown on an expanded time scale (lower traces). (C-E) Superimposed traces from the control, control+UCL1684, 3-AP and 3-AP+UCL1684 conditions.

increased $(0.53 \pm 0.02 \mathrm{~ms}$ in control rats and $0.65 \pm 0.05 \mathrm{~ms}$ in 3-AP-treated rats, $\mathrm{p}<0.05$; Fig. $2 \mathrm{C}$ ) by 3 -AP treatment. However, treatment did not affect the peak amplitude of the action potentials $(52.16 \pm 3.2 \mathrm{mV}$ in control and $50.61 \pm 2.7 \mathrm{mV}$ in ataxic groups; Fig. 2D) but did significantly reduce the AHP amplitude $(-5.82 \pm 0.25 \mathrm{mV}$ and $-4.5 \pm 0.2 \mathrm{mV}$ in control and ataxic groups, respectively, $\mathrm{p}<0.01$; Figs $1 \mathrm{C}$ and $2 \mathrm{D}$ ).

Next, the evoked firing characteristics of PCs were investigated. With a membrane potential of $-60 \mathrm{mV}$, trains of action potentials were elicited in both the control and ataxic conditions when the weak $(0.1 \mathrm{nA})$ and strong $(0.5 \mathrm{nA})$ depolarizing current pulses $(1600 \mathrm{~ms}$ duration) were injected. The reciprocal of the interspike interval (1/first ISI) between the first two action potentials was used to compare the initial instantaneous firing frequency of PCs in response to the pulses of depolarizing current. In comparison to the control condition, treatment with 3-AP caused a significant increase in the initial discharge frequency during a train of action potentials that was evoked by injecting a strong depolarizing pulse $(0.5 \mathrm{nA}, \mathrm{p}<0.001, \mathrm{n}=15$, Fig. $3 \mathrm{~A})$. The value of this parameter in control rats was $95.42 \pm 5.17 \mathrm{~Hz}$ and $135.89 \pm 6.09 \mathrm{~Hz}$ in the ataxic group. However, there was no significant difference between the control and 3-AP-treated groups in response to weak $(0.1 \mathrm{nA})$ depolarizing current injections (Fig. 3A).
In addition, to further quantify the effect of 3-AP treatment on the responses evoked by depolarizing current injections, the spike frequency adaptation ratio was calculated. In ataxic rats, the mean SFA ratio calculated for the trains of action potentials evoked by $0.5 \mathrm{nA}$ current steps was significantly lower $(40 \%$, $\mathrm{P}<0.05$ ) than in control groups (from $2.18 \pm 0.33$ to $1.35 \pm 0.07$; Fig. $3 \mathrm{~B}$ ), and therefore, the frequency of the action potential discharge was increased in Purkinje neurons from the ataxic group (Fig. 3C).

Contribution of small conductance $K^{+}$channels to intrinsic properties of cerebellar Purkinje neurons: a comparison between ataxic and control conditions

To determine the functional role of SK channels and their contribution to the intrinsic properties of PCs, the effect of UCL1684, a high-affinity blocker of SK channels (SK1-3), was assessed both in the control and ataxic conditions. In control Purkinje cells, a bath application of UCL1684 (60 nM) caused the firing pattern to become irregular (Fig. 1Aii), and a marked reduction in the firing regularity was observed when the firing coefficient of variation (a useful parameter to describe the firing regularity) of PCs was compared to the control conditions. This difference was evidenced by a significant increase in the CV $(0.23 \pm 0.05, \mathrm{p}<0.001$; Fig. 2B). 

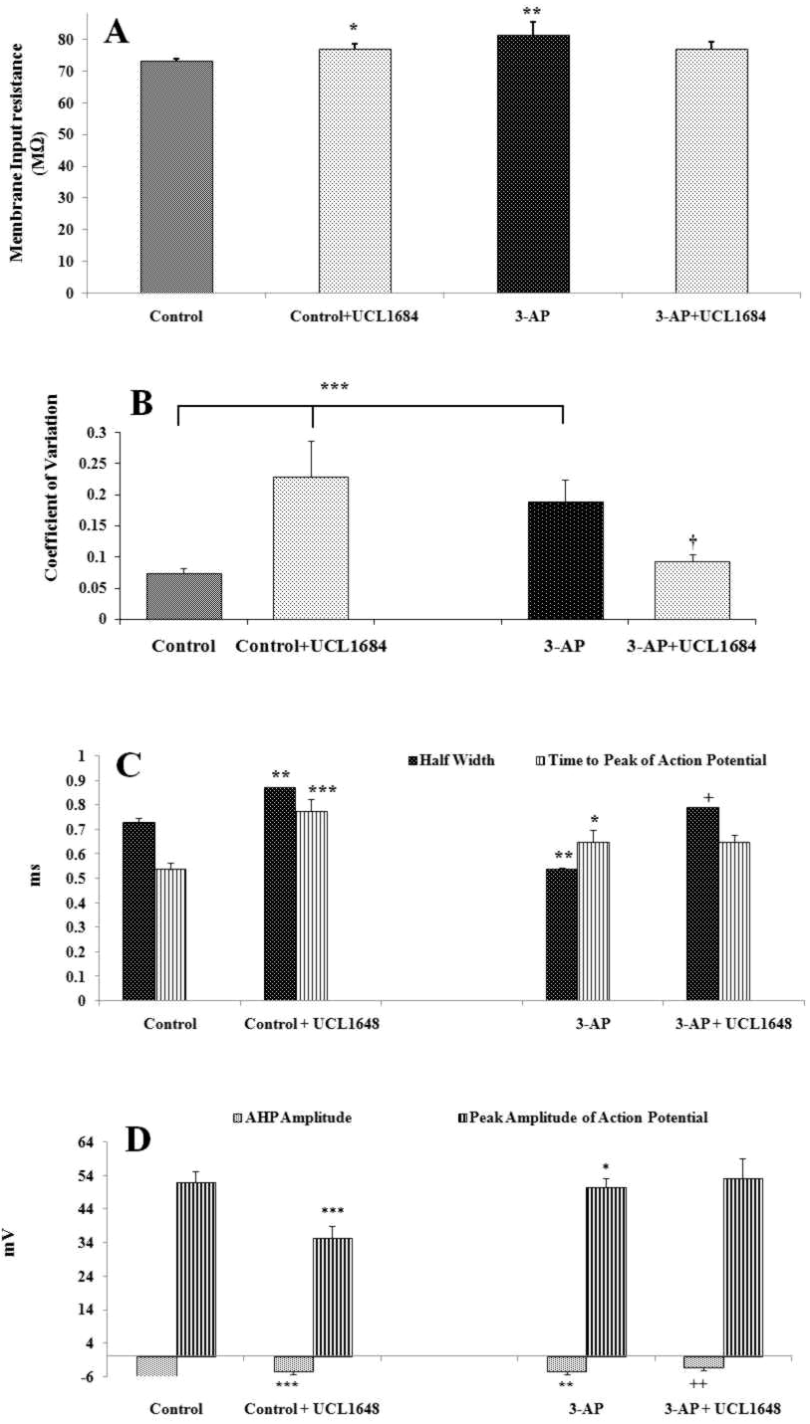

Fig. 2. UCL 1684 differentially influences the electrophysiological properties of PCs from normal and ataxic rats. (A) Effects of 3-AP treatment and SK channel blockade on membrane input resistance. (B) Summary data of the mean coefficient of variation of spontaneous action potentials under the control conditions and the 3-AP and UCL 1684 treatments. The effects of 3-AP treatment and SK channel blockade by UCL $1684(60 \mathrm{nM})(\mathbf{C})$ on the half width and the time to peak of the action potential and (D) on the AHP amplitude and the peak amplitude of action potentials. *, **, ***, significantly different $(\mathrm{P}<0.05, \mathrm{P}<0.01$, $P<0.001)$ from control;,+++ , significantly different $(P<0.05$, $\mathrm{P}<0.01$ ) from the 3-AP-treated group.

A blockade of the SK channels also increased the membrane input resistance $(77.03 \pm 1.47 \mathrm{M} \Omega, \mathrm{P}<0.05$; Fig. 2A). The firing activity in the Purkinje neurons from ataxic rats became very regular (Fig. 1Bii), and the coefficient of variation of the interspike interval was significantly decreased $(0.09 \pm 0.01, \mathrm{p}<0.05$; Fig. 2B); however, the mean membrane resistance remained unchanged in the presence of UCL 1684. Alterations in the parameters of the action potentials upon application of UCL 1684 were also explored. In the control conditions, UCL 1684 significantly increased the time to peak of the action potentials $(0.77 \pm 0.04 \mathrm{~ms}, \mathrm{P}<0.001$, Fig. 2C) and the half width of the action potentials $(0.87 \pm 0.02 \mathrm{~ms}, \mathrm{p}<0.01$; Fig. 2C) but significantly decreased both the peak amplitude of the action potentials (35.41 $\pm 3.4 \mathrm{mV}, \mathrm{p}<0.001)$ and the AHP amplitude $(-4.41 \pm 0.1 \mathrm{mV}, \mathrm{p}<0.001$; Fig. 2D). However, the blockade of the SK channels by UCL 1684 neither significantly changed the time to peak nor affected the peak amplitude of the action potentials in the ataxic rats (Figs 2C and D), but it caused a significant increase in the duration of the action potentials $(0.79 \pm 0.002 \mathrm{~ms}, \mathrm{p}<0.05$; Fig. 2C) and a significant reduction in the AHP amplitude $(-3.29 \pm 0.17 \mathrm{mV}, \mathrm{p}<0.01$; Fig. 2D).

Next, we examined whether UCL 1684 could differentially affect the evoked firing responses of PCs in the control and ataxic conditions. The application of UCL 1684 significantly increased the initial firing frequencies in the trains of action potentials elicited by injection with a strong depolarizing current pulse $(0.5 \mathrm{nA})$ but not in response to a weak $(0.1 \mathrm{nA})$ current step, in both control $(160.86 \pm 20.1, \mathrm{p}<0.05)$ or ataxic rats $(159.24 \pm 8.03$, $\mathrm{p}<0.05$; Fig. 3A).

Furthermore, UCL $1684(60 \mathrm{nM})$ in Purkinje neurons from control but not from ataxic rats significantly reduced the spike frequency adaptation (from $2.18 \pm 0.33$ to $1.34 \pm 0.16, \quad \mathrm{p}<0.05$ ), thereby enhancing Purkinje neuronal excitability (Figs 3B-D).

\section{Discussion}

The present study examined the functional consequences of alterations in the intrinsic properties of Purkinje neurons in an animal model of ataxia induced by neurotoxin 3-AP. The electrophysiological findings demonstrated that, in ataxic rats, plastic changes in the intrinsic electrophysiological properties of Purkinje neurons were produced. These changes were manifested as an increase in the firing irregularity that was accompanied by a significant increase in $\mathrm{CV}_{\text {ISI }}$, a decrease in the time to peak and a significant decrease in the half width and the AHP amplitude. Both the decrease in the firing precision and the AHP amplitude could be attributed to the suppression of SK potassium channels (Hallworth et al. 2003). This decrease was also associated with a significant increase in the initial instantaneous frequency and a decrease in the SFA ratio in response to the strong depolarizing pulse. To further determine the 


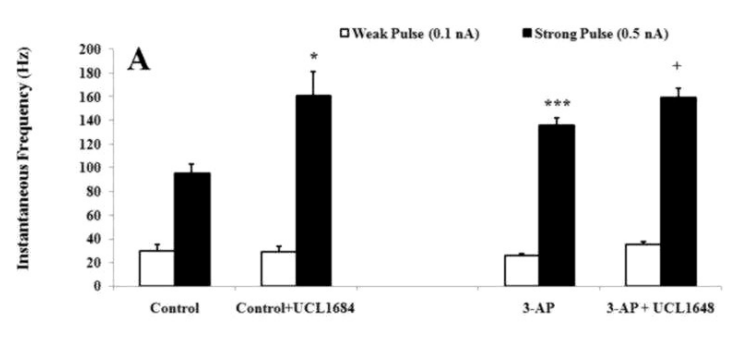

竎

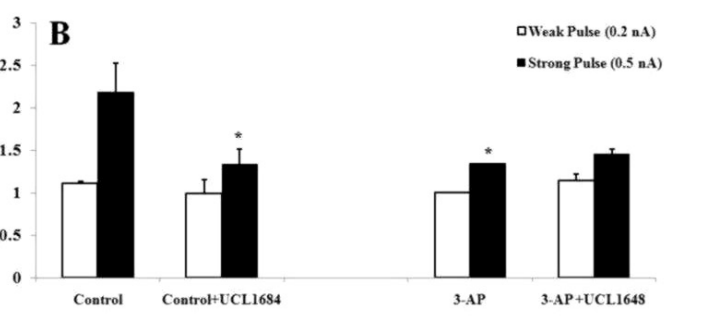

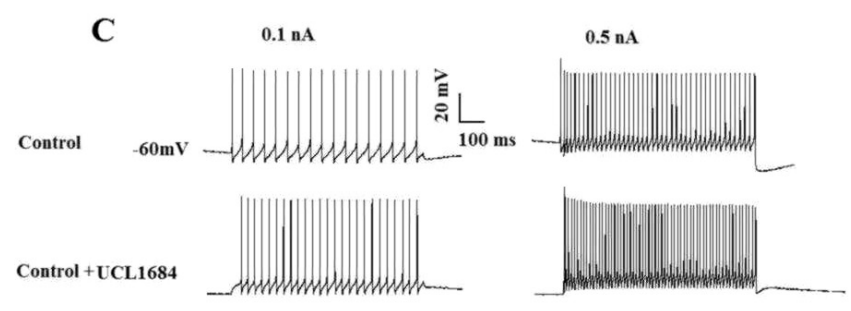

D
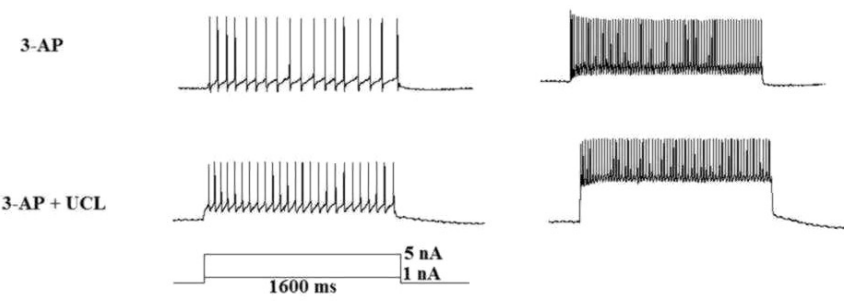

Fig. 3. Effects of 3-AP treatment and UCL 1684 application on evoked firing responses of Purkinje neurons. (A) Histogram showing the first instantaneous firing frequency (1/first ISI) for low and high frequency discharges evoked by weak (0.1 nA) and strong (0.5 nA) depolarizing current pulses (1600 ms), both in the control and ataxic conditions before and after UCL 1684 treatments. (B) Comparison of the spike frequency adaptation (SFA) ratio before and after a bath application of UCL 1684 (60 nM) in the control and ataxic conditions. (C and D) Representative traces illustrating the differences in action potential firing recorded from Purkinje neurons in control and ataxic groups when elicited by depolarizing current injections ( $0.1 \mathrm{nA}$, left and $0.5 \mathrm{nA}$, right) before and after SK channel blockade by UCL1684. $*, * *, * * *$, significantly different $(\mathrm{p}<0.05, \mathrm{p}<0.01, \mathrm{p}<0.001)$ from controls; + , significant difference $(\mathrm{p}<0.05)$ from 3-AP treated (ataxic) groups.

possible mechanism(s) underlying such alterations in the intrinsic electrophysiological behavior of PCs, the effects of SK channel blockade on the intrinsic properties of PCs were investigated. The present work indicated that the blockade of SK channels by UCL 1684 (60 nM) produced effects in control Purkinje neurons that were almost entirely distinct from those recorded in ataxic rats; the blockade of these channels disrupted the precision of the firing in control PCs, but it decreased the irregularity of the firing pattern while restoring the precision of the firing in PCs from ataxic rats, as evidenced by a significant increase and decrease in CVs, respectively. The action potential parameters and the evoked firing characteristics of control PCs appeared to be more profoundly affected by SK channel blockade than did those in the ataxic condition.

Previous studies have demonstrated that PCs are capable of firing intrinsically even in the absence of synaptic inputs (Llinás and Sugimori 1980, Häusser and Clark 1997, Raman and Bean 1999, Womack and Khodakhah 2002). However, distinct synaptic inputs are necessary for producing distinct neuronal output responses. Purkinje neurons receive two excitatory inputs from a climbing fibre and additional input from many parallel fibres. Olivary climbing fibre discharge plays an important role in regulating cerebellar function by controlling the intrinsic properties of PCs (Cerminara and
Rawson 2004, McKay et al. 2007, Janahmadi et al. 2009). Inactivating or chemically destroying the inferior olive climbing fibre system has been shown to result in marked modifications in the spike firing behavior of Purkinje cells (Colin et al. 1981, Montarolo et al. 1982, Cerminara and Rawson 2004, Janahmadi et al. 2009). In agreement with previously published data, here we observed a marked alteration in the intrinsic excitability of Purkinje cells from ataxic rats. Neuronal intrinsic excitability plays a critical role in the transition of synaptic inputs to the particular output function; hence, alterations in the intrinsic properties of neuronal cells may profoundly affect the functioning neuronal circuits. We have recently demonstrated that abolition of the inferior olivary climbing fibre using neurotoxin 3-AP caused changes in the intrinsic firing pattern of PCs, which was associated with a decrease in the precision of firing, and that pretreatment with combined riluzole and 3-AP restored the normal intrinsic properties (Janahmadi et al. 2009), thereby improving the motor performance of rats. It was assumed that the neuroprotective action of riluzole was due to the opening of intrinsic SK channels. It has also been previously shown that the precision of pacemaking in PCs is maintained mainly by $\mathrm{K}_{\mathrm{Ca}}$ channels (Womack and Khodakhah 2003, Womack et al. 2004); thus, the reduction of $\mathrm{K}_{\mathrm{Ca}}$ channel activity may be the main cause of firing irregularity in the PCs of ataxic mice 
(Sausbier et al. 2004, Walter et al. 2006). Nevertheless, the functional contribution of $\mathrm{K}^{+}$channels, particularly SK channels, to the intrinsic electrophysiological properties of PCs in the ataxic condition has not yet been fully determined.

A marked alteration in the first instantaneous firing frequency, and thus the interspike interval, in response to the strong current pulse $(0.5 \mathrm{nA})$, but not a weak step, following 3-AP treatment indicates that SK channels, which are important for controlling early spike frequency adaptation, have undergone functional changes. Therefore, the effects of potent SK channels blockers on the intrinsic electrophysiological properties of PCs in control and ataxic conditions were assessed.

Possible ionic mechanisms underlying plastic changes in the intrinsic properties of PCs following 3-AP-induced ataxia

Ataxia is a neurological disease characterized by a lack of balance and coordination; the decreased neuronal firing precision may be an underlying mechanism (Sausbier et al. 2004, Shakkottai et al. 2004, Walter et al. 2006). To determine the functional role of SK channels in firing irregularity, the effects of UCL 1684, a potent SK blocker (Dunn 1999), on intrinsic electrophysiological properties of PCs were compared between control and ataxic conditions. The blockade of SK channels induced firing irregularity, changed the action potential shape, suppressed the AHP amplitude, increased both the half width and the firing frequency and decreased the SFA ratio in the control condition. Blockade of these channels also produced similar effects on the half width, the AHP amplitude and the initial firing frequency of PCs in the ataxic group. However, in ataxic rats, the blockade of SK channels led to an increase in the firing precision but left the SFA ratio unchanged. These findings suggest the differential contribution of SK channels to the intrinsic excitability of PCs in normal and ataxic conditions, possibly because of plastic alterations in the intrinsic properties of the PCs that occurred in the ataxic condition. Cerebellar Purkinje neurons express $\mathrm{Ca}^{2+}$-activated $\mathrm{K}^{+}$channels on their soma and dendrites (Gahwiler and Llano 1989, Knaus et al. 1996, Jacquin and Gruol 1999, Cingolani et al. 2002), which are activated by $\mathrm{Ca}^{2+}$ influx through $\mathrm{P} / \mathrm{Q}$ type voltage-gated calcium channels (Vergara et al. 1998, Womack et al. 2004). BK channels contribute to the electrophysiological properties of PCs, including action potential repolarization and fast AHP that follows a single action potential (Edgerton and Reinhart 2003, Womack and Khodakhah 2003, 2004, McKay and Turner 2004). In contrast, SK channels play a pivotal role in shaping the neuronal firing pattern (Wolfart et al. 2001, Cloues and Sather 2003) and in regulating spike frequency adaptation (Yen et al. 1999, Pedarzani et al. 2005, Brosh et al. 2006, Vatanparast and Janahmadi 2009) in many nerve cells, including PCs. SK channels, which are voltageinsensitive and blocked by apamin, a bee venom toxin (Hallworth et al. 2003, Sah 1996), play a role in setting the intrinsic firing frequency (Edgerton and Reinhart 2003) and contribute to a slow AHP current that may last several seconds following bursts of action potentials (Marrion and Tavalin 1998, Sotcker et al. 1999, Bowden et al. 2001). These channels are active at membrane potentials that are close to the cell resting potential in mature PCs and participate in the regulation of neuronal hyperexcitability and burst firing (Haghdoost et al. 2007).

Considering the suppressive effect of UCL 1684 on the AHP amplitude, an increase in the neuronal excitability and a decrease in the regularity of firing were expected in the control group; however, in the ataxic condition, blockade of the SK channels decreased the firing regularity and induced an irregular firing pattern in the PCs. These results suggest that SK channels play an important role in regulating the firing behavior: the dysfunction of these channels potentially may contribute to the disruption of the normal firing behavior of PCs seen in ataxic rats. It is believed that the AHP enhances the precision of firing (Deister et al. 2009); therefore, the firing irregularity observed in the presence of UCL 1684 in control PCs could be due to the blockade of the SK channel, which is responsible for the action potential AHP. Apamin, a selective blocker of SK channels, has also been reported to induce an irregular firing pattern in dopaminergic neurons of the substantia nigra (Lovejoy et al. 2001) and midbrain (Ji et al. 2009).

In addition, UCL 1684 significantly decreased the SFA ratio in the control conditions but not in the ataxic conditions, suggesting that SK channels play a significant role in affecting early spike frequency adaptation in normal PCs; this result may reflect the down-regulation of SK channels in the ataxic condition. Several mechanisms have been proposed to underlie early SFA, including a slow activation of outward currents, a slow reduction in inward currents, the summation of the AHP, and a reduction in the availability of fast $\mathrm{Na}^{+}$ channels (Miles et al. 2005, Gu et al. 2007, Vatanparast and Janahmadi 2009). Here a reduction in both the peak 
amplitude of the action potential and the AHP amplitude and an increase in the time of peak imply that a reduction in $\mathrm{Na}^{+}$channel availability and/or summation of the AHP could be the most likely underlying mechanisms of SFA in the control conditions, but not in the ataxic conditions. However, further voltage clamp study is needed to address this issue. There is also evidence supporting the involvement of the AHP in the SFA phenomenon in other cell types, where blockade of AHP conductance leads to reductions in spike frequency adaptation (Madison and Nicoll 1984).

\section{Conclusions}

In conclusion, the present data strongly support the idea that cerebellar ataxia, induced by neurotoxin
3-AP, led to profound changes in the intrinsic properties of Purkinje neurons and altered the functional characteristics of potassium channels, possibly $\mathrm{Ca}^{2+}$ activated $\mathrm{K}^{+}$channels, which could be the key mechanisms underlying this intrinsic plasticity. It could be proposed that such alterations might be related to the motor impairment observed in 3-AP-treated (ataxic) rats.

\section{Conflict of Interest}

There is no conflict of interest.

\section{Acknowledgements}

This work was sponsored by a grant (No. 85032/14) from Iran National Science Foundation (INSF) and supported by Deputy of Research, Shahid Beheshti Medical School.

\section{References}

BALABAN CD: Central neurotoxic effects of intraperitoneally administered 3-acetylpyridine, harmaline and niacinamide in Sprague-Dawley and Long-Evans rats: a critical review of central 3-acetylpyridine neurotoxicity. Brain Rev 9: 21-42, 1985.

BOWDEN SEH, FLETCHER S, LOANE DJ, MARRION NV: Somatic colocalization of rat SK1 and D class (Cav 1.2) L-type calcium channels in rat CA1 hippocampal pyramidal neurons. $J$ Neurosci 175: 1-6, 2001.

BROSH I, ROSENBLUM K, BARKAI E: Learning-induced reversal of the effect of noradrenaline on the postburst AHP. J Neurophysiol 96: 1728-1733, 2006.

CADDY KW, VOZEH F: The effect of 3-acetylpyridine on inferior olivary neuron degeneration in Lurcher mutant and wild-type mice. Eur J Pharmacol 330: 139-42, 1997.

CERMINARA NL, RAWSON JA: Evidence that climbing fibers control an intrinsic spike generator in cerebellar Purkinje cells. J Neurosci 24: 4510-4517, 2004.

CINGOLANI LA, GYMNOPOULOS M, BOCCACCIO A, STOCKER M, PEDARZANI P: Developmental regulation of small-conductance $\mathrm{Ca}^{2+}$-activated $\mathrm{K}^{+}$channel expression and function in rat Purkinje neurons. $J$ Neurosci 22: 4456-4467, 2002.

CKAY BE, TUNER RW: Kv3 K $\mathrm{K}^{+}$channels enable burst output in rat cerebellar Purkinje cells. Eur J Neurosci 20: 729$739,2004$.

CLOUES RK, SATHER WA: Afterhyperpolarization regulates firing rate in neurons of the suprachiasmatic nucleus. J Neurosci 23: 1593-1604, 2003.

COLOIN F, MANIL J, DESCLIN JC: The olivocerebellar system, I. Delayed and slow inhibitory effects: an overlooked salient feature of cerebellar climbing fibers. Brain Res 187: 3-27, 1981.

DANIEL H, RANCILLAC A, CREPEL F: Mechanisms underlying cannabinoid inhibition of presynaptic $\mathrm{Ca}^{2+}$ influx at parallel fiber synapses of the rat cerebellum. J Physiol 557: 159-174, 2004.

DEISTER C, CHABN C, SURMEIER DJ, WILSON CJ: Calcium-activated SK channels influence voltage- gated ion channels to determine the precision of firing in globus pallidus neurons. J Neurosci 29: 8452-8461, 2009.

DUNN PM: UCL 1684: a potent blocker of $\mathrm{Ca}^{2+}$-activated $\mathrm{K}^{+}$channels in rat adrenal chromaffin cells in culture. Eur $J$ Pharmacol 368: 119-123, 1999.

EDGERTON JR, REINHART PH: Distinct contributions of small and large conductance $\mathrm{Ca}^{2+}$-activated $\mathrm{K}^{+}$channels to rat Purkinje neuron function. J Physiol Lond 548: 53-69, 2003.

FABER ES, SAH P: Physiological role of calcium-activated potassium currents in the rat lateral amygdale. $J$ Neurosci 22: 1618-1628, 2002. 
GAHWILER, BH, LLIANO I: Sodium and potassium conductances in somatic membranes of rat Purkinje cells from organotypic cerebellar cultures. J Physiol Lond 417: 105-122, 1989.

GOUDARZI I, KAFFASHIAN M, SHABANI M, HAGHDOOST-YAZDI H, BEHZADI G, JANAHMADI M: In vivo 4-aminopyridine treatment alters the neurotoxin 3-acetylpyridine-induced plastic changes in intrinsic electrophysiological properties of rat cerebellar Purkinje neurones. Eur J Pharmacol 642: 56-65, 2010.

GU N, VERVAEKE K, STORM JF: BK potassium channels facilitate high-frequency firing and cause early spike frequency adaptation in rat CA1 hippocampal pyramidal cells. J Physiol Lond 580: 859-882, 2007.

HAGHDOOST-YAZDI H, JANAHMADI M, BEHZADI G: The role of small-conductance $\mathrm{Ca}^{2+}$-activated $\mathrm{K}^{+}$channels in the modulation of 4-aminopyridine-induced burst firing in rat cerebellar Purkinje cells. Brain Res 1156: 5966, 2007.

HALLWORTH NE, WILSON CJ, BEVAN MD: Apamin-sensitive small conductance calcium-activated potassium channels, through their selective coupling to voltage-gated calcium channels, are critical determinants of the precision, pace, and pattern of action potential generation in rat subthalamic nucleus neurones in vitro. J Neurosci 23: 7525-7542, 2003.

HAÜSSER M, CLARK BA: Tonic synaptic inhibition modulates neuronal output pattern and spatiotemporal synaptic integration. Neuron 19: 665-67, 1997.

JANAHMADI M, GOUDARZI I, KAFFASHIAN MR, BEHZADI G, FATHOLLAHI Y, HAJIZADEHS: Co-treatment with riluzole, a neuroprotective drug, ameliorates the 3-acetylpyridine induced neurotoxicity in cerebellar Purkinje neurones of rats: behavioural and electrophysiological evidence. Neurotoxicology 30: 393-402, 2009.

JI H, HOUGAARD C, ERRIK KF, STRØBAEK D, CHRISTOPHRSEN P, HEPARD PD: Tuning the excitability of midbrain dopamine neurons by modulating the $\mathrm{Ca}^{2+}$ sensitivity of SK channels. Eur J Neurosci 29: 1883-1895, 2009.

KNAUS HG, SCHWARZER C, KOCH RO, EBRERHART A, KACZOROWSKI GJ, GLOSSMANN H, WUNDER F, PONGS O, GARCIA ML, SPERK G: Distribution of high-conductance $\mathrm{Ca}^{2+}$-activated $\mathrm{K}^{+}$channels in rat brain: targeting to axons and nerve terminals. J Neurosci 16: 955-963, 1996.

LLINÁS R, WALTON K, HILLMAN DE, SOTELO C: Inferior olive: its role in motor learning. Science 190: 12301231, 1975.

LLINÁS R, SUGIMORI M: Electrophysiological properties of in vitro Purkinje cell somata in mammalian cerebellar slices. J Physiol Lond 305: 171-195, 1980.

LOEWENSTEIN Y, MAHON S, CHADDERTON P, KITAMURA K, SOMPOLINSKY H, YAROM Y, HAÜSSER M: Bistability of cerebellar Purkinje cells modulated by sensory stimulation. Nat Neurosci 8: 202-211, 2005.

LOVEJOY LP, SHEPARD PD, CANAVIER CC: Apamin-induced irregular firing in vitro and irregular single-spike firing observed in vivo in dopamine neurons is chaotic. Neurosci 104: 829-840, 2001.

MAINGERT F, COSTE B, HAO J, GIAMARCHI A, ALLEN D, CREST M, LITCHFIELD DW, ADELMAN JP: Neurotransmitter modulation of small-conductance $\mathrm{Ca}^{2+}$-activated $\mathrm{K}^{+}$channels by regulation of $\mathrm{Ca}^{2+}$ gating. Neuron 59: 439-449, 2008.

MADISON DV, NICOLL RA: Control of the repetitive discharge of rat CA 1 pyramidal neurones in vitro. $J$ Physiol Lond 354: 319-331, 1984.

MARRION NV, TAVALIN SJ: Selective activation of $\mathrm{Ca}^{2+}$-activated $\mathrm{K}^{+}$channels by co-localised $\mathrm{Ca}^{2+}$ channels in hippocampal neurons. Nature 395: 900-905, 1998.

MCKAY BE, ENGBERS JDT, MEHAFFEY WH, GORDON GRJ, MOLINEUX ML, BAINS JS, TUNER RW: Climbing fiber discharge regulates cerebellar function by controlling the intrinsic characteristics of Purkinje cell output. J Neurophysiol 97: 2590-2604, 2007.

MILES GB, DAI Y, BROWNSTONE RM: Mechanisms underlying the early phase of spike frequency adaptation in mouse spinal motoneurones. J Physiol Lond 566: 519-532, 2005.

MOLDAVAN MG, IRWIN RP, ALLEN CN: Presynaptic $\mathrm{GABA}_{\mathrm{B}}$ receptors regulate retinohypothalamic tract synaptic transmission by inhibiting voltage-gated $\mathrm{Ca}^{2+}$ channels. J Neurophysiol 95: 3727-3741, 2006.

MONTAROLO PG, PALESTINI M, STRATA P: The inhibitory effect of the olivocerebellar input on the cerebellar Purkinje cells in the rat. J Physiol Lond 332: 187-202, 1982. 
PEDARZANI P, MOSBACHER J, RIVARD A, CINGOLANI LA, OLIVER D, STOCKER M, ADELMAN JP, FAKLER B: Control of electrical activity in central neurons by modulating the gating of small conductance $\mathrm{Ca}^{2+}$-activated $\mathrm{K}^{+}$channels. J Biol Chem 276: 9762-9769, 2001.

RAMAN IM, BEAN BP: Ionic currents underlying spontaneous action potentials in isolated cerebellar Purkinje neurons. J Neurosci 19: 1663-1674, 1999.

RUSSO MJ, YAU HJ, NUNZI MG, MUGNAINI M, MARTINA M: Dynamic metabotropic control of intrinsic firing in cerebellar unipolar brush cells. J Neurophysiol 100: 3351-3360, 2008.

SAH P: $\mathrm{Ca}^{2+}$-activated $\mathrm{K}^{+}$currents in neurones: types, physiological roles and modulation. Trends Neurosci 19: 150154, 1996.

SAUSBIER M, HU H, ARNTZ C, FEIL S, KAMM S, ADELSBERGER H, SAUSBIER U, SAILER CA, FEIL R, HOFMANN F, KORTH M, SHIPSTON MJ, KNAUS HG, WOLFER DP, PEDROARENA CM, STORM JF, RUTH P: Cerebellar ataxia and Purkinje cell dysfunction caused by $\mathrm{Ca}^{2+}$-activated $\mathrm{K}^{+}$channel deficiency. Proc Natl Acad Sci USA 101: 9474-9478, 2004.

SEOANE A, APPS R, BALBUENA E, HERRERO L, LLORENS J: Differential effects of trans-crotononitrile and 3-acetylpyridine on inferior olive integrity and behavioural performance in the rat. Eur J Neurosci 22: 880-894, 2005.

SCHULZ DJ: Plasticity and stability in neuronal output via changes in intrinsic excitability: it's what's inside that counts. $J$ Exp Biol 209: 4821-4827, 2006.

SHAH M, HAYLETT DG: $\mathrm{Ca}^{2+}$ channels involved in the generation of the slow afterhyperpolarization in cultured rat hippocampal pyramidal neurons. J Neurophysiol 83: 2554-2561, 2000.

SHAKKOTTAI VG, CHOU CH, ODDO S, SAILER CA, KNAUS HG, GUTMAN GA, BARISH ME, LAFERLA FM, CHANDY KG: Enhanced neuronal excitability in the absence of neurodegeneration induces cerebellar ataxia. J Clin Invest 113: 582-590, 2004.

SHEPARD PD, BUNNEY BS: Repetitive firing properties of putative dopamine-containing neurons in vitro: regulation by an apamin-sensitive $\mathrm{Ca}^{2+}$-activated $\mathrm{K}^{+}$conductance. Exp Brain Res 86: 141-150, 1991.

SLESINGER PA, PATIL N, LIAO YJ, JAN YN, JAN LY, COX DR: Functional effects of the mouse weaver mutation on G protein-gated inwardly rectifying $\mathrm{K}^{+}$channels. Neuron 16: 321-331, 1996.

SMITH SL, OTI TS: Persistent changes in spontaneous firing of Purkinje neurons triggered by the nitric oxide signaling cascade. J Neurosci 23: 367-372, 2003.

STOCKER M, KRAUSE M, PEDARZANI P: An apamin-sensitive $\mathrm{Ca}^{2+}$-activated $\mathrm{K}^{+}$channel subunit, SK1, SK2 and SK3, in the adult rat central nervous system. Mol Cell Neurosci 15: 476-493, 1999.

STONE TW: Neuropharmacology of quinolinic and kynurenic acids. Pharmacol Rev 45: 309-379, 1993.

TORRES-ALEMAN I, BARRIOS V, LLEDO A, BERCIANO J: The insulin-like growth factor system in cerebellar degeneration. Ann Neurol 39: 335-342, 1996.

VATANPARAST J, JANAHMADI M: Contribution of apamin-sensitive SK channels to the firing precision but not to the slow afterhyperpolarization and spike frequency adaptation in snail neurons. Brain Res 1255: 57-66, 2009.

VERGARA C, LATORRE R, MARRION NV, ADELMAN JP: Calcium-activated potassium channels. Curr Opin Neurobiol 8: 321-329, 1998.

VENANCE L, GLOWINSKI J: Heterogeneity of spike frequency adaptation among medium spiny neurones from the rat striatum. Neuroscience 122: 77-92, 2003.

WOMACK MD, KHODAKHAH K: Active contribution of dendrites to the tonic and trimodal patterns of activity in cerebellar Purkinje neurons. J Neurosci 22: 10603-10612, 2002.

WOMACK MD, KHODAKHAH K: Smatic and dendritic small-conductance calcium-activated potassium channels regulate the output of cerebellar Purkinje neurons. J Neurosci 23: 2600-2607, 2003.

WOMACK MD, CHEVEZ C, KHODAKHAH K: Calcium-activated potassium channels are selectively coupled to P/Q-type calcium channels in cerebellar Purkinje neurons. J Neurosci 24: 8818-8822, 2004.

WALTER JT, ALVIŇA K, WOMACK MD, CHEVEDZ C, KHODAKHAH K: Decreases in the precision of Purkinje cell a pacemaking cause cerebellar dysfunction and ataxia. Nat Neurosci 9: 389-397, 2006. 
WILLAMS SR, CHRISTENSEN SR, STUART GJ, HÄUSSER M: Membrane potential bistability is controlled by the hyperpolarization-activated current $\mathrm{I}_{\mathrm{H}}$ in rat cerebellar Purkinje neurons in vitro. J Physiol Lond 539: 469-483, 2002.

WOLFART J, NEUHOFF H, FRANZ O, ROEPER J: Differential expression of the small-conductance, calciumactivated potassium channel SK3 is critical for pacemaker control in dopaminergic midbrain neurons. J Neurosci 21: 3443-3456, 2001.

YEN JC, CHAN JY, CHAN SH: Involvement of apamin-sensitive SK channels in spike frequency adaptation of neurons in nucleus tractus solitarii of the rat. J Biomed Sci 6: 18-24, 1999.

YOON KW, COVEY DF, ROTHMAN SM: Multiple mechanisms of picrotoxin block of GABA-induced currents in rat hippocampal neurons. J Physiol Lond 464: 423-439, 1993. 